\title{
REFLEXÕES ACERCA DO FAZER ÉTICO NA CLÍNICA GESTÁLTICA: UM ESTUDO EXPLORATÓRIO
}

\author{
Reflections on ethical making in clinical gestalt: an exploratory study \\ Reflexiones sobre la ética en la clínica de la Gestalt: un estudio exploratorio
}

Lázaro Castro Silva Nascimento

Kamilly SouZa do VAle

\begin{abstract}
Resumo: A discussão do tema Ética, por vezes, se fecha na deontologia. Contudo, tal discussão extrapola esse recorte e alcança outra dimensão no que compete ao fazer ético em psicoterapia, não unicamente baseado em leis e diretrizes. Esta pesquisa discute o fazer ético na prática psicoterapêutica em Gestalt-terapia. Utilizou-se uma abordagem qualitativa orientada a partir do método fenomenológico de Sanders. O projeto foi aprovado previamente pelo Comitê de Ética em Pesquisa a fim de garantir as questões éticas ligadas à pesquisa. Foram realizadas entrevistas com seis psicólogas da cidade de Belém/PA, escolhidas a partir do método bola de neve com dois critérios de inclusão: ser profissional formado em Psicologia e especialista em Gestalt-terapia. As entrevistas foram analisadas a partir da fenomenologia e de conceitos gestálticos. Foi possível ampliar a compreensão acerca do fazer ético gestáltico destacando-se a importância do cuidado com quem busca atendimento; a necessidade do psicoterapeuta de realizar a suspensão fenomenológica; o preparo técnico refinado; a relevância do trabalho de psicoterapia pessoal do gestalt-terapeuta; e a ética pessoal enquanto premissa para uma ética profissional. Pesquisas futuras na área mostram-se importantes para que seja possível manter a fluidez dessas compreensões acerca da temática abordada.
\end{abstract}

Palavras-chave: Ética; Gestalt-terapia; Método fenomenológico.

Abstract: The discussion of the topic Ethics sometimes is limited to deontology. However, this discussion goes beyond this cut and reaches another dimension in ethical making in psychotherapy, not only based on laws and guidelines. This research discusses the ethical making in Gestalt therapy. It was used a qualitative approach driven from the phenomenological method of Sanders. The project was approved by the Ethics Committee in Research to ensure the ethical issues related to research. Interviews were conducted with six psychologists of Belém, chosen from the snowball method with two criteria: have professional degree in Psychology and have a specialist title as Gestalt therapist. The interviews were analyzed using the phenomenology and Gestalt concepts. It was possible to expand the understanding of making ethical gestalt highlighting the importance of taking care of those seeking care, the need of the psychotherapist to suspend their "a priori", the refined technical preparation, the importance of a personal psychoterapy work for the gestalt therapist; and personal ethics as a premise for a professional ethic. Future research in the area is important to make possible to maintain the fluidity of these insights about the theme.

Keywords: Ethics; Gestalt therapy; Phenomenological method.

Resumen: La discusión de tema Ética a veces se cierra en la deontología. Sin embargo, esta discusión va más allá de este corte y alcanza otra dimensión, ya que el hacer ético en psicoterapia, no es hecho sólo en base a las leyes y directrices. Esta investigación trata sobre la ética en la terapia Gestalt. Se utilizó un enfoque cualitativo impulsado desde el método fenomenológico de Sanders. El proyecto fue aprobado por el Comité de Ética en Investigación para garantizar los aspectos éticos relacionados con la investigación. Las entrevistas se llevaron a cabo con seis psicólogas de la ciudad de Belém, elegido el método de bola de nieve con dos criterios: ser profesional en Psicología y se especializa en la terapia Gestalt. El análisis fue realizado a partir de la fenomenología y conceptos Gestalt. Fue posible ampliar la comprensión acerca de la ética en terapia Gestalt destacando la importancia de cuidar de aquellos que buscan la atención, la necesidad del psicoterapeuta para suspender sus “a priori”, la preparación técnica refinada, la importancia dela psicoterapia personal para el terapeuta Gestalt, y la ética personal como premisa de una ética profesional. La investigación futura en el área es importante para mantener la fluidez de estos puntos de vista sobre el tema.

Palabras-clave: Ética; Terapia Gestalt; Método fenomenológico.

\section{Introdução}

A formação em Psicologia, de maneira geral, privilegia diversas perspectivas teóricas, filosóficas e temas transversais como Sociologia, Filosofia, Biologia, Antropologia, Direitos Humanos entre outros. Muito se discute, nos anos de formação, acerca de áreas de atuação, abordagens psicológicas, casos clínicos, psicopatologia e vários outros temas. Contudo, há temáticas, como a Ética, que carecem de discussão aprofundada.

Em um contexto mais amplo, para pensar esta temática, é relevante também refletir sobre o momento sócio- 
-histórico atual. Acreditando no pensamento heideggeriano de que as pessoas são seres-no-mundo, é impossível descolar a discussão acerca da Ética do momento em que as relações se estabelecem, ou seja, no presente. Para pensar esta contemporaneidade, Bauman (2011) traz o conceito de pós-modernidade enquanto uma época em que há desconstruções de valores antigos, dúvidas e fragmentações, em um mundo em que tudo passa a acontecer de forma rápida, utilitarista e efêmera.

Extrapolando a questão da clínica tradicional, Neto \& Penna (2006) afirmam que a sociedade espera do psicólogo, em qualquer área em que este trabalhe, uma "habilidade clínica" mesmo quando a prática de psicoterapia estiver distante das funções que o mesmo exerça naquele contexto. Há que se destacar o movimento nos últimos anos que tem buscado a descentralização do papel do psicólogo na prática clínica privada, enfatizando um trabalho mais voltado ao social, como a clínica ampliada. Contudo, isso não significa que o espaço da clínica particular tenha se perdido e não exija novas pesquisas voltadas para este. Assim, discutir questões éticas no campo clínico propicia reflexões que transcendem este espaço e atendem a uma demanda que é esperada dos profissionais da/na área.

Os objetivos deste trabalho são: discutir algumas questões éticas envolvidas na prática psicoterapêutica sob o enfoque gestáltico, bem como discutir acerca dos conceitos sobre ética e/em psicoterapia gestáltica; e refletir sobre a importância de um fazer ético na prática profissional do gestalt-terapeuta.

\section{1. $A(s)$ ética(s)}

Entre as definições mais comuns do termo, é possível citar a compreensão da Ética enquanto ramo da Filosofia. O termo vem da palavra grega "ethiké" e significa: "parte da Filosofia que estuda os valores morais e os princípios ideais da conduta humana. É ciência normativa que serve de base à Filosofia prática” (Michaelis, 2001).

Mostra-se interessante ainda diferençar os termos ética e moral, usualmente confundidos e considerados como sinônimos.

A diferença entre ética e moral é que a moral prescreve o que se deve crer, pensar, fazer sob um modelo ideal e perfeito do Bem; a ética, diversamente, convida a agir e a pensar segundo o que um corpo pode, de acordo com a potência da natureza que o atravessa (Fuganti, 1990, p. 51).

A confusão no cotidiano talvez surja pela proximidade, no plano da prática, em que ética e moral estão presentes, ambas ligadas aos ideais que orientam as condutas humanas diariamente. Contudo, enquanto a Ética estaria mais próxima do campo da "reflexão sobre" uma determinada ação, a moral estaria mais focada no fazer, nos atos praticados. Ainda sobre o dilema "ética e moral”, Morin (2005), logo no início de seu livro O Método 6 -Ética, auxilia na busca por uma integração entre as duas palavras:

Busca-se, com freqüência, distinguir ética e moral. Usemos "ética" para designar um ponto de vista supra ou meta-individual; "moral" para situar-nos no nível da decisão e da ação dos indivíduos. Mas a moral individual depende implícita ou explicitamente de uma ética. Esta se resseca e esvazia sem as morais individuais. Os dois termos são inseparáveis e, às vezes, recobrem-se (Morin, 2005, p. 15, grifos nossos).

A Ética, ou melhor, "As Éticas" podem ser estudadas também através de recortes históricos diversos. Aranha \& Martins (2009) discorrem sobre as éticas a partir da reflexão grega, trazendo o pensamento de Platão e Aristóteles, em seguida apresentando as concepções do período medieval e do pensamento moderno, para, enfim, discutir sobre a ética contemporânea. Cortina \& Martínez (2005) fazem uma extensa revisão histórica acerca da Ética e apontam que esta teria uma tripla função, sendo:

1) esclarecer o que é a moral, quais são seus traços específicos; 2) fundamentar a moralidade, ou seja, procurar averiguar quais são as razões que conferem sentido ao esforço dos seres humanos de viver moralmente; e 3) aplicar aos diferentes âmbitos da vida social os resultados obtidos nas duas primeiras funções, de maneira que se adote nesses âmbitos sociais uma moral crítica (ou seja, racionalmente fundamentada), em vez de um código moral dogmaticamente imposto ou da ausência de referências morais (Cortina \& Martínez, 2005, p. 21).

O sociólogo Bauman (2011, p. 23) questiona ainda sobre a necessidade de se buscar uma ética baseada em códigos de condutas organizados por "peritos éticos". Assim, enfatiza que a ética pós-moderna pode ser colocada em prática cotidianamente por pessoas comuns, criticando a forma como se perdeu, na pós-modernidade, a confiança no próprio julgamento, passando esta função aos "especialistas em ética". Dessa forma, a sociedade assume uma postura passiva diante da reflexão sobre suas práticas.

Outra proposta para estudar o tema das éticas diz respeito à ética aplicada. Esta pode ser compreendida da seguinte maneira:

A história do pensamento ético do último terço do século XX caracteriza-se pelo crescente interesse na solução dos problemas de ordem individual e coletiva que preocupam as pessoas e a humanidade no seu dia-a-dia. [...] Se a ética, de forma geral, se ocupa do que é correto ou incorreto no agir humano, a ética 
aplicada trata de questões relevantes para a pessoa e a humanidade. Um tema é eticamente relevante quando considerado pela maioria dos seres racionais, exemplificando, o uso sem limites dos recursos naturais (Clotet, 1997, s/p).

A ética aplicada, portanto, busca não mais uma reflexão apenas no âmbito do imaterial, pensando a dicotomia "bom versus mau", mas se ocupa de questões cotidianas na contemporaneidade. Pensando partes do todo "ética", é possível inserir a bioética no conceito de ética aplicada. E entre a Bioética e Psicologia, para Ludwig, Zogbi, Redivo \& Muller (2005), o ponto central das discussões se encontraria basicamente no respeito ao ser humano.

Alinhado com a questão do respeito ao ser humano, é possível pensar o cuidado com este semelhante. Boff (1999) discute sobre a ética do cuidado, afirmando que é no cuidado com o outro que se encontra o ethos fundamental do ser humano. O referido autor também discute a questão da Ética buscando compreensões sobre a forma como essa reflexão constante sobre o mundo, sobre outro e sobre si emerge. Acreditando que o "eu” só surge a partir do "tu", desta relação com o outro semelhante e com este mundo, ele afirma que:

(...) o nascimento da ética reside nesta relação de responsabilidade diante do rosto do outro [...]. É na acolhida ou na rejeição, na aliança ou na hostilidade para com o rosto do outro que se estabelecem as relações mais primárias do ser humano e se decidem as tendências de dominação ou de cooperação (Boff, 1999, p. 139).

Morin (2005) discute sobre a ética complexa, considerando a religação indíviduo-espécie-sociedade, a qual fundamenta a sua proposta de uma teoria do pensamento complexo. Assim, propõe que em vez de segregar e dissecar a Ética, devemos buscar compreendê-la de forma ampliada e totalizante.

Outra perspectiva que tange à Ética diz respeito aos códigos de ética, ou também à chamada deontologia, a qual se refere a um conjunto de princípios e deveres de uma determinada profissão. Tal proposta de um código de ética visa orientar o profissional acerca dos possíveis dilemas com os quais possa vir a se encontrar em sua atuação. Neste caso fala-se em uma ética profissional, a qual pode ser definida da seguinte forma:

A ética profissional é a aplicação da ética no campo das atividades profissionais; a pessoa tem que estar imbuída de certos princípios ou valores próprios do ser humano para vivê-los nas suas atividades de trabalho (Camargo, citado por Passos, 2007, p. 79).

A partir destes recortes teóricos, é possível perceber a riqueza e a complexidade dos estudos voltados acerca do tema Ética (ou Éticas). Contudo, faz-se necessário aprofundamento específico no que diz respeito aos objetivos deste trabalho.

\section{Gestalt-terapia e ética gestáltica}

A Gestalt-terapia (GT) se insere no campo das psicoterapias humanistas fazendo parte da chamada "terceira força” das abordagens psicológicas surgidas nos anos 50 do século XX. Com uma proposta inovadora, a teoria inicialmente pensada por Fritz Perls a partir de críticas à psicanálise carrega consigo a máxima: "Não há nenhuma função do organismo que não seja essencialmente um processo de interação no organismo/ambiente" (Perls, Hefferline \& Goodman 1951/1997, p. 205).

Buscando teorizar acerca da nova abordagem que surgia dentro das correntes psicológicas, Yontef (1998) comparou a GT às abordagens comportamental e psicodinâmica, destacando o conceito de aqui-agora e awareness: "A modificação comportamental condiciona pelo controle dos estímulos, a psicanálise cura por falar a respeito e pela descoberta do problema mental (o problema) e a Gestalt-terapia traz a autopercepção por experimentos aqui-e-agora em awareness dirigida” (p. 20).

Acerca da proposta de campo de Lewin, Pinto (2009) aprofunda e mostra a importância dessa conceituação para a perspectiva da Gestalt-terapia:

Para a abordagem gestáltica, o campo é primário, a experiência surge do campo, o self e o outro são processos do campo, nossas escolhas configuram o campo, enquanto significados surgem de interações com o campo, e não nos são dados a priori. Para a Gestalt-terapia, a ênfase é no vivido (Pinto, 2009, p. 21).

Com esta perspectiva integradora, foi possível a saída de uma proposta determinante acerca do ser humano e a partida para uma nova forma, mais complexa, atualmente corroborada pelos estudos do sociólogo Edgar Morin (2010; 2011). Seus estudos se referem ao conceito de complexo como algo que integra, em vez de fragmentar e compartimentar, e ao mesmo tempo reconhece o inacabado e a incompletude de qualquer conhecimento.

Polster \& Polster (1973/2001) também destacam a importância da experiência, porém com foco no momento aqui-agora do encontro terapêutico:

O trabalho da psicoterapia é alterar o senso que o indivíduo tem de seu fundo, de modo que tais experiências novas possam agora ser harmoniosas com sua natureza. Ele precisa descobrir que as experiências não são inevitavelmente o que ele achava que seriam, que de fato elas são bem-vindas, e que por meio dessas experiências em mudança, seu fundo se altera e passa a ser possível ter harmonia em sua vida (p. 49). 
Anos mais tarde, Perls (1973/1988), insatisfeito com as proposições de suas obras Ego, Fome e Agressão e GestaltTerapia, buscava, antes de findar sua existência, clarificar alguns conceitos e torná-los mais acessíveis à população em geral, assim define a proposta gestáltica em terapia:

A terapia gestáltica é uma terapia experiencial, mais que uma terapia verbal ou interpretativa. Pedimos ao paciente para não falar sobre seus traumas e problemas da área remota do passado e da memória, mas para reexperienciar seus problemas e traumas - que são situações inacabadas no presente - no aqui e agora (Perls, 1973/1988, p. 76).

A partir dessas compreensões sobre as bases que fundamentam a prática da Gestalt-terapia, é possível destacar um enfoque específico acerca da ética gestáltica:

A ética na Gestalt-terapia se dá através de um inclinar-se diante de, de um expor-se a, de um aprender com. [...] escuta cuidadosa, onde o respeito é fundamental. Respeito pela experiência pessoal e singularidade do outro, pela sua capacidade de se auto-significar, de fazer suas escolhas, de criar e recriar sua subjetividade. Esta é a experiência ética por excelência, a de, a partir de sua própria singularidade, reconhecer o outro em sua alteridade (Bernardini, 1999).

A partir de Frazão (2008), é possível pensar uma visão de fazer ético gestáltico de forma integrada e ampliada, sendo importante para esta gestalt-terapeuta ser ético para um fazer ético, considerando questões amplas que envolvem o mundo, as demandas sociais e o respeito. Para ela, "todas essas questões incidem sobre a questão ética” (p. 36).

Távora, Quadros \& Soares (2009) comentam sobre a ética gestáltica a partir do pensamento de Martin Buber, afirmando que:

O pensamento de Buber nos ajuda a pensar a ética da Gestalt-terapia: ética da diversidade, da inclusão, da ação transformadora. É a possibilidade de estar com o outro no exercício da dialogicidade, numa relação entre diferentes onde privilegia-se a diferença, sendo assim, a melhor maneira de descobrir-se e de criar-se $(\mathrm{s} / \mathrm{p})$.

Já para Bloom (2009), a ética relacional da Gestaltterapia não seria uma ética de como se deve ser em relação ao outro, dando-lhe direções, mas sim uma inevitável ética que implica em responsabilidade.

A partir destes teóricos, é possível compreender a ética gestáltica pautada nas bases da dialogicidade, do respeito, da vivência de um ser ético no cotidiano e da noção existencialista de responsabilidade. Sendo estes pontos constituintes de um fazer clínico ético gestáltico.
Partindo deste recorte ético, com enfoque gestáltico, foram investigadas algumas compreensões acerca do que vem a ser um fazer ético gestáltico a partir da narrativa da experiência de gestalt-terapeutas da cidade de Belém, Pará.

\section{Caminhos teórico-metodológicos}

Os procedimentos teórico-metodológicos utilizados foram: a) pesquisa de revisão bibliográfica acerca das temáticas Ética e Gestalt-terapia; b) seleção dos informantes por meio da rede de relações dos pesquisadores e dos próprios informantes (método bola de neve); c) contato telefônico, presencial ou via e-mail preliminar com os participantes para obter a concordância verbal/escrita em participar da pesquisa; d) encontro pessoal para realização de entrevistas semiestruturadas individuais, gravadas e posteriormente transcritas; e) análise e discussão dos dados obtidos. O projeto deste trabalho foi aprovado pelo Comitê de Ética em Pesquisa do Instituto de Ciências da Saúde da Universidade Federal do Pará (ICS/UFPA) através do meio eletrônico Plataforma Brasil sob o número do CAAE 12551713.7.0000.0018.

Neste trabalho optou-se pela utilização do Método Fenomenológico de Sanders, no qual a estrutura fenomenológica da pesquisa pode ser compreendida a partir de três eixos: 1) determinação de limites sobre "o que" (assuntos que não buscam quantificação) e "quem" (pessoas que possam oferecer informações sobre o fenômeno estudado) é investigado; 2) a coleta de dados (a partir de entrevistas com participantes, gravadas e transcritas); e 3) a análise fenomenológica dos dados (Moreira, 2002, p. 121).

Para tal análise dos dados é preciso realizar uma redução fenomenológica, Forghieri (2004) explicita dois momentos fundamentais para que isso seja possível: 1) envolvimento existencial, em que o investigador precisa "colocar fora de ação os conhecimentos por ele já adquiridos sobre a vivência que está pretendendo investigar, para então tentar abrir-se a essa vivência” (p. 60); e, 2) distanciamento reflexivo, no qual o pesquisador precisa "estabelecer um certo distanciamento da vivência, para refletir sobre essa sua compreensão e tentar captar e enunciar, descritivamente, o seu sentido ou o significado daquela vivência em seu existir" (p. 60).

Além disso, Sanders (citado por Moreira, 2002) destaca que na análise dos dados o importante para a delimitação de um tema não é a frequência com que este emerge, mas sim sua centralidade e a sua importância. Após identificá-los, o investigador organiza os temas em conjuntos que, após conclusão da pesquisa, irão caracterizar a estrutura do fenômeno estudado.

Neste estudo, foram entrevistadas seis psicólogas com idade entre 29 e 54 anos e com especializações na Abordagem Gestáltica concluídas entre 1994 e 2011. Os critérios de inclusão para compor a amostra foram apenas 
dois: ser profissional formado em Psicologia com atuação na área clínica e possuir especialização em Gestaltterapia. A quantidade de participantes também foi baseada na recomendação de Sanders, que sugere entre 3 a 6 informantes para trabalhar em profundidade um determinado fenômeno.

Para escolha das participantes foi utilizado o método não probabilístico de amostragem bola de neve, considerado por Turato (2003) como adequado para pesquisas qualitativas. $\mathrm{O}$ pesquisador investiga, ouve uma participante que pode oferecer dados sobre o tema estudado e após a entrevista, a participante era solicitada pelo pesquisador a indicar uma ou duas pessoas para participarem da pesquisa. Quando havia mais de uma indicação, o pesquisador arbitrava e escolhia apenas uma indicação para dar prosseguimento à coleta dos dados. Apenas a primeira participante foi escolhida baseada na rede prévia de contatos do pesquisador.

O pesquisador entrava em contato com a participante por telefone, apresentava-se, explicitava brevemente os seus objetivos e perguntava sobre o interesse da mesma em participar. Após consentimento verbal, era marcada a entrevista de acordo com a agenda da participante. A coleta era iniciada pelo pesquisador após assinatura prévia do Termo de Consentimento Livre e Esclarecido e autorização verbal para gravação da entrevista. O roteiro de entrevista foi composto por três perguntas objetivas acerca do objeto de pesquisa deste trabalho e informações sobre as participantes, em alguns casos algumas perguntas foram aprofundadas baseadas nas respostas das informantes. As perguntas que compuseram o questionário foram: 1) Como você compreende a ética na clínica? 2) Considerando a sua experiência profissional, o que é para você um fazer clínico ético em Gestalt-terapia? 3) Cite alguns exemplos do que você considera um fazer não-ético na clínica gestáltica.

Após entrevista, os dados foram transcritos de forma fiel ao conteúdo, preservando erros de concordâncias e afins, sem qualquer tipo de correção, permitindo, assim, maior fidelidade quanto às informações oferecidas pelos participantes da pesquisa. Apenas os nomes foram substituídos por siglas (P1, P2, P3, P4, P5 e P6) a fim de garantir o sigilo previamente garantido com o termo de consentimento livre e esclarecido.

A construção das categorias foi baseada em conceitos que compõem a Gestalt-terapia, a Fenomenologia e questões da deontologia profissional. A partir da leitura e de releituras das entrevistas foram destacadas as unidades de significado.

Távora, Quadros \& Soares (2009) afirmam que para se chegar a compreender algo são necessárias várias aproximações para ampliar o exame de um tema em foco, contrastando os olhares e buscando o exercício do diálogo. Além disso, através da visão gestáltica, podemos perceber o positivo, o potencialmente transformador, mesmo diante dos limites e dificuldades (Pereira, 2008).

A organização dos resultados foi dividida em duas partes, a primeira com os dados das informantes e a outra com as unidades de significado 1) "Compreensões acerca da ética na Psicologia clínica”, 2) "Fazer ético gestáltico/ Fazer não-ético gestáltico” e suas respectivas categorias, buscando, assim, atender aos objetivos inicialmente propostos neste trabalho. Para evitar repetições, em algumas categorias apenas alguns excertos foram inseridos, dando-se preferência para os que os pesquisadores acreditavam melhor representá-las.

\section{Resultados e discussão}

\subsection{Perfil das informantes}

O questionário utilizado na pesquisa incluía um cabeçalho com informações básicas sobre as participantes, sendo estas: idade, ano de formação e ano de especialização em Gestalt-terapia. A fim de facilitar a visualização destas informações, foi construída uma tabela a partir dos dados coletados:

Tabela 1

Perfil das participantes.

\begin{tabular}{|c|c|c|c|}
\hline Participante & Idade & Ano de formação em Psicologia & Ano de especialização em Gestalt-terapia \\
\hline P1 & 46 anos & 1989 & 1994 \\
\hline P2 & 54 anos & 1992 & 2000 \\
\hline P3 & 51 anos & 1990 & 2000 \\
\hline P4 & 40 anos & 1995 & 1996 \\
\hline P5 & 29 anos & 2009 & 2011 \\
\hline P6 & 42 anos & 2006 & 2011 \\
\hline
\end{tabular}

\subsection{Compreensões acerca da ética na psicologia clínica}

Esta unidade de significado é composta pelas categorias referentes às diferentes apreensões sobre a ética na Psicologia clínica para as participantes, sendo a ética enquanto: respeito (P1, P4 e P5), cuidado e acolhimen- to (P2 e P6), algo inerente ao ser (P3) e responsabilidade com o outro (P4 e P6). Ética para P1, P4 e P5, está atrelada a ideia de Ética enquanto respeito, no que compete às questões contratuais, aos sentimentos que emergem no psicoterapeuta durante o atendimento e ao conteúdo que é trazido como queixas para os encontros. 
Bernardini (1999) traz a dimensão do respeito enquanto algo primordial para uma atitude ética. Afirma que "um dos fundamentos da atitude gestáltica é o respeito intrínseco pela diversidade e pelas diferenças". Destacando a importância de respeitar o outro e respeitar a si mesmo como formas de possibilitar um fazer ético gestáltico. Discurso que emerge na fala de P1:

P1: Então, a ética na clínica, eu penso que perpassa por esse respeito em todos os sentidos, tanto respeitando essa questão contratual, quanto o funcionamento do cliente, né? Como ele se apresenta.

As participantes P2 e P6 compreendem a Ética enquanto cuidado e acolhimento, atuando a partir de um cuidado do psicoterapeuta com o seu cliente, afirmando a necessidade de se colocar a serviço deste semelhante que busca auxílio. Apresenta-se a fala da Participante (P2):

\section{P2: [...], o mais importante na ética é como eu recebo e acolho esta pessoa.}

Assim, a Ética estaria embasada tanto no cuidado em receber o cliente, na forma como conduzir os atendimentos, bem como no acolhimento. Bernardini (1999) afirma que o acolhimento é a ética essencial em Gestalt-terapia:

Acolher o sujeito na sua diferença, olhando-o como a pessoa que é, realmente consciente de que ele é essencialmente diferente de mim e acolhê-lo em sua alteridade é a meu ver a experiência ética essencial na prática da Gestalt-terapia e na vida (Bernardini, 1999).

Já a participante P3 possui um olhar totalizante sobre a ética, afirmando que para ela, a ética na clínica é uma continuidade de uma ética pessoal fora deste espaço de atuação. Estando, assim, essa qualidade internalizada no psicoterapeuta enquanto pessoa, não unicamente a partir de condutas profissionais, entendendo a Ética enquanto inerente ao ser:

P3: Então, eu compreendo a ética a partir da pessoa. Eu acho que é a ética é uma questão, ela não antecede o ser, mas ela vem junto com o ser, né, então eu acho que ser ético na clínica é uma continuidade de um ser ético da pessoa.

As falas de P3 e P4 apontaram para a existência de uma ética pessoal que antecede a ética na prática profissional. Tais discursos corroboram a ideia de Ayres \& Botelho (2009) quando afirmam que "a integridade pessoal/profissional parece-nos um binômio fundamental e imprescindível a uma atitude ética”. Dessa forma, não existiria uma ética desvinculada do âmbito pessoal.

As participantes P4 e P6 destacaram também, além do respeito e do cuidado, a noção da Ética enquanto res- ponsabilidade com o outro que busca atendimento clínico. A compreensão de responsabilidade do psicoterapeuta na abordagem gestáltica aparece em Perls (1973/1988) quando afirma que "A responsabilidade fundamental do terapeuta é não deixar sem questionamento qualquer afirmação ou atitude que não sejam representativas do si-mesmo, que sejam evidência da falta de responsabilidade do cliente" (p. 92).

Assim, esta noção de responsabilidade é importante tanto para o cliente que se ajusta neuroticamente quanto para o gestalt-terapeuta, o qual precisa estar implicado de maneira comprometida com o seu fazer.

\subsection{Fazer ético gestáltico/Fazer não-ético gestáltico}

Nesta categoria foram organizadas as informações referentes ao que as participantes julgavam como fazer ético e fazer não-ético na abordagem gestáltica. A utilização do termo "não-ético" deu-se para possibilitar uma discussão mais ampliada, evitando que esta discussão ficasse restrita apenas a deontologia da profissão.

Para as participantes um fazer ético em Gestalt-terapia está diretamente associado à Crença na autorregulação organísmica. Segundo Lucca (2007, p. 31), a proposta de que o ser humano realiza sua autorregulação surgiu com Kurt Goldstein que, ao questionar o modelo atomístico utilizado pelas ciências biológicas de meados do século XX, propôs a utilização do pensamento organísmico descobrindo, através de estudos neurofisiológicos, essa tentativa de ajuste do organismo.

As participantes P1, P3 e P6 destacam, portanto, a importância do gestalt-terapeuta em reconhecer que 0 seu cliente tem a potencialidade para ajustar-se da melhor maneira que puder. Não cabendo ao profissional psicólogo com orientação gestáltica deliberar sobre o que deve ser feito ou como o cliente deve agir, respeitando o seu potencial de autorregulação. Elencou-se o discurso de P1:

P1: acreditar na autorregulação do cliente, acreditar e, quando eu falo em autorregulação, é que ele tem o poder de encontrar ajustes possíveis pra ele tá saindo de uma determinada situação ou encontrando a melhor forma possível, que ele tenha de se autorregular.

Para as participantes P1 e P3 um fazer não-ético seria o não Acolhimento e respeito às escolhas. Destacam em seus discursos a importância de respeito às escolhas:

P1: não respeitar as escolhas, a liberdade dessa pessoa, então isso é um fazer não-ético.

Ribeiro (1999) explicita brevemente a ideia de escolha para a abordagem gestáltica afirmando que "escolher é colocar-se entre a intra e a intersubjetividade e isso 
nos coloca diante dos nossos limites” (p. 91). Tal noção de escolha advém da corrente filosófica existencialista. Respeitar as escolhas do cliente é creditar a ele a responsabilidade por si e, assim, colocar-se como um heterossuporte para que este possa sustentar aquilo que escolheu, reconhecendo-se neste processo de escolha. Vinculado a esta ideia de respeitar as escolhas de quem busca atendimento, é possível pensar o acolhimento. Acolher essa pessoa que chega procurando compreender um pouco mais de si mesma. A noção de acolhimento emergiu nos discursos de P2, P3 e P6.

Buscar oferecer acolhimento à pessoa e ao sofrimento que esta traz para o atendimento psicoterapêutico, portanto, mostra-se como um ponto importante para um fazer gestáltico comprometido com a ética. É o acolhimento a estas demandas que, em muitos casos, possibilita que o cliente consiga ampliar sua percepção sobre si e buscar formas de ajustar-se dentro do que lhe é possível.

As participantes revelaram em seu discurso a importância do Cuidado enquanto atuação ética. A noção de cuidado para Boff (2012) é extremamente ampla, o autor chega a afirmar que "o cuidado é aquela condição prévia que permite um ser vir à existência. É o orientador antecipado de nossas ações para que sejam construtivas e não destrutivas”. Essa compreensão é fundamental para o posicionamento ético no trabalho psicoterapêutico.

Emergiram, a partir desta ideia, três subcategorias: cuidado com o outro, apropriação da linguagem e sagrado - valorização do cliente. A importância desse cuidado com o outro, com este ser que busca a psicoterapia foi evidenciada nos discursos de P2, P3, P4 e P6. Aqui revelada no discurso de P4:

P4: Então, primeiramente, eu entendo ética como algo que se doa, que emerge da pessoa, como uma atitude espontânea, de manutenção de cuidado, de cuidado consigo, de cuidado com o planeta, de cuidado com o semelhante, de cuidado com os parâmetros profissionais. Então eu não vejo que exista ética só como um parâmetro, um ditame profissional.

Esta ideia de ética ampliada, a qual exige um cuidado não somente com o outro, mas com o mundo, com a sociedade e com o meio em que vivemos reafirma as compreensões já mencionadas de Boff (1999), bem como a de Frazão (2008):

A ética precisa se fazer presente a todo momento no nosso viver. A postura ética no mundo antecede a postura ética de um fazer no mundo. Ética é consciência e responsabilidade; é não apenas uma postura no mundo, mas também diante do mundo. (Frazão, 2008, p. 36)

A participante $\mathrm{P} 4$ destaca a necessidade de adequação da linguagem do psicoterapeuta como uma forma de cui- dado com o seu cliente, assim sendo fundamental para a mesma a Apropriação da linguagem:

P4: [...] às vezes coisas simples dizem respeito ao cuidado e à ética. Por exemplo, você adequar a linguagem, você ter uma atitude que você efetivamente possa se encontrar com o outro naquilo que é o parâmetro, o mundo, a referência do outro.

Pinto (2009) recomenda esse cuidado com a comunicação diante da pessoa que busca atendimento psicoterapêutico, afirmando que o psicoterapeuta deve usar "linguagem e postura acessíveis ao cliente, levando em conta sua ansiedade e sua insegurança momentânea, de maneira que ele possa compreender adequadamente o que lhe é dito" (p. 164). Compreende-se que pensar e viver a ética gestáltica, é estar integrado com um visão de homem ancorada na perspectiva existencial-fenomenológica, aonde partirá do sujeito o sentido e o significado que o mesmo dará para seus fenômenos, sendo o psicoterapeuta um facilitador deste processo.

Sabe-se, no entanto que é fundamental que o profissional de Psicologia ancorado por qualquer abordagem de sua escolha esteja atento para a ética profissional exigida pelo Conselho Federal de Psicologia, que apresenta parâmetros a serem seguidos. No discurso das participantes acerca da Ética Profissional apresentaram-se questões mais voltadas para a deontologia profissional, especificamente as subcategorias sigilo e contrato, setting terapêutico, fundamentação teórica e supervisão/encaminhamento.

Emergiram nas falas de P1, P2 e P5 a subcategoria Sigilo e contrato. Sabe-se que questão do sigilo é uma das mais abordadas acerca do trabalho psicoterapêutico, sendo claramente explicitada no artigo $9^{\circ}$ do Código de Ética Profissional do Psicólogo (Conselho Federal de Psicologia, 2005). Quanto à questão do contrato, para Rosa (2011), este pode ser iniciado a partir do que o cliente traz para a psicoterapia e como o psicoterapeuta identifica esta demanda com seu cliente, revelando-se para ambos quais serão os encaminhamentos dados no trabalho.

Já o setting terapêutico envolve questões objetivas, como o espaço, a iluminação, conforto e afins, e também questões subjetivas, que dizem respeito, por exemplo, à preparação do gestalt-terapeuta e a sua disponibilidade interna. Quanto à questão objetiva, esta categoria emergiu no discurso de P2:

P2: o desrespeito de uma forma geral: chegar atrasado, não tá nem aí pro cliente, não ter um ambiente adequado de ruídos, de barulhos, então, isso é muito importante a gente tá atento pra isso.

No que compete às questões subjetivas, foi possível encontrar no discurso de P4 a importância da psicoterapia pessoal do clínico e no discurso de P5 um destaque à disponibilidade para o atendimento: 
P4: Eu acho que um fazer ético em Gestalt-terapia envolve fundamentalmente três aspectos. Um: psicoterapia pessoal do clínico. Eu não consigo conceber uma pessoa que cuide do outro se ela não tiver pra consigo uma atitude de cuidado. Então, a primeira coisa é psicoterapia pessoal, é o trabalho pessoal do clínico.

O fazer clínico ético gestáltico estaria, assim, pautado tanto no cuidado em relação ao espaço do atendimento, com uma sala adequada dentro das possibilidades, bem como em relação ao preparo pessoal e técnico do gestalt-terapeuta. Corroborando a ideia de Boff (1999) sobre como o cuidado com o outro e o cuidado consigo são indissociáveis.

As participantes P2, P3 e P4 destacaram a importância da fundamentação teórica para o desenvolvimento de uma prática ética em GT.

P4: o estudo teórico da abordagem de forma concisa, séria, aprofundada, o psicoterapeuta precisa, se ele se intitula gestalt-terapeuta, ele precisa recorrentemente, constantemente, pensar teoricamente sobre o seu fazer.

Tal necessidade de fundamentação teórica se estende não apenas à Gestalt-terapia, mas a toda atividade exercida pelo profissional em Psicologia. Isso é explicitado na apresentação do Código de Ética do Psicólogo em suas primeiras linhas:

Toda profissão define-se a partir de um corpo de práticas que busca atender demandas sociais, norteado por elevados padrões técnicos e pela existência de normas éticas que garantam a adequada relação de cada profissional com seus pares e com a sociedade como um todo (Conselho Federal de Psicologia, 2005, p. 5).

Cabe destacar, porém, que os códigos de ética da profissão não precisam ser amarras para o profissional. Antes disso, devem ter a função de orientar e possibilitar uma reflexão dentro de alguns contextos mais generalistas e outros mais específicos. Cabendo ao gestalt-terapeuta, também, a capacidade de ajustar-se criativamente diante das demandas que emergem no cotidiano.

A necessidade de troca entre os pares também surgiu como uma questão ética a ser considerada (P4). Além disso, a importância de reconhecer a própria limitação diante de uma demanda, exigindo, portanto, um encaminhamento para outro profissional, também emergiu nos dados coletados (P3). Destacando-se a necessidade eventual de Supervisão/Encaminhamento.

P4: o processo de supervisão ou de troca entre os pares. A prática clínica é um espaço muito solitário, então esse movimento de interação, interlocução com os pares, no sentido de repensar posturas, de ouvir um posicionamento de um outro profissional.
A supervisão clínica é fundamental no processo de aprendizado de terapeutas iniciantes, independente de sua abordagem teórica. É neste espaço que são possíveis as trocas e a ampliação do seu autossuporte. Soares (2009) afirma que "A supervisão pode adquirir a função de conectar o graduando com o mundo, promovendo o desdobramento da percepção que tem de sua experiência proporcionando-lhe a ampliação de recursos pessoais" (p. 156).

Pinto (2009) comenta sobre a capacidade de reconhecer quando não se está apto a atender uma determinada demanda sendo necessário o encaminhamento do cliente a outro profissional. As participantes relataram ainda a importância da suspensão fenomenológica (P2, P3, P5 e P6) e da inclusão (P3) para o fazer clínico ético em Gestalt-terapia:

P3: Eu acho que eu compreendo a ética desta forma, né, quando eu não pego os meus valores morais, mas sei bem deles, quais são, e consigo me diferenciar do cliente, e consigo lidar com a dor do cliente a partir dele, e não de mim. Eaí, entrar nessa questão do julgamento e da avaliação, que não cabe naquele momento.

Polster \& Polster (1973/2001) apresentam a proposta de suspensão fenomenológica ao considerarem o processo de "colocar entre parênteses" como fundamental para a comunicação na terapia. Ao passo que a inclusão é compreendida como "uma atitude permissiva, na qual o terapeuta entende e aceita a outra pessoa, sem julgar a atitude ou o comportamento do outro, de forma positiva ou negativa" (Yontef, 1988, p. 252).

São estas duas habilidades do gestalt-terapeuta que permitirão que este seja capaz de ouvir uma demanda clínica sem julgar o seu cliente. Ou ainda, que seja capaz de separar as suas demandas pessoais das que lhe são apresentadas por quem busca atendimento. Ao citar os conceitos de Martin Buber, partindo, portanto, de uma concepção da Relação dialógica, a participante P2 mostra a importância de compreender a relação com 0 cliente em diferentes momentos, ora no princípio Eu-Tu e ora, Eu-Isso:

P2: [...] quando eu estou com o cliente eu tento estar nessa relação eu-tu, mas quando ele já vai embora, que eu preciso estudar, que eu preciso ver, eu tô numa relação eu-isso. Tá? Eu já tô vendo ele como o meu, digamos, o meu objeto de estudo, por questões teóricas. [...] No momento que eu trato um cliente como simplesmente um objeto, a relação eu-isso, eu tô fugindo da ética.

A proposta de Buber (1923/1981) sobre a dialogicidade discorre sobre duas esferas em que as relações ocorrem. Na relação Eu-Tu, em que o contato é genuíno e interessado, há uma busca do outro em toda sua potencialidade, 
ocorrendo no presente, no momento do agora. Contudo, na relação Eu-Isso, não há um outro ser ali, antes, há um objeto, uma atividade, uma coisa. Ambas as relações são fundamentais para existir no mundo, havendo a necessidade de saber alterná-las.

A participante P2 destaca com clareza a importância de recorrer a estas duas possibilidades de relação, compreendendo o momento em que o cliente está diante do psicoterapeuta com uma necessidade de uma relação EuTu. Destaca, porém, a necessidade de, após a sua partida, compreender este processo a partir da teoria, estabelecendo uma relação Eu-Isso, assimilando o que foi trazido pelo cliente durante a sessão. Corroborando com esta perspectiva foi encontrada nos discursos de P4 e P5 a subcategoria Relacionamento horizontal enquanto respeito:

P4: Especificamente a ética na nossa profissão, a prática clínica atravessada pelo parâmetro ético, é você [...] estar diante do seu cliente com uma atitude genuína de interesse e respeito, a partir do momento que você se coloca diante do outro genuinamente, numa condição de escuta interessada e respeitosa.

Yontef (1988), fazendo menção a Buber, afirma que as relações Eu-Tu são horizontais ao passo que relações no modelo Eu-Isso acabam tornando-se verticais. O diálogo e o respeito genuínos com a pessoa que busca a psicoterapia são os motes que irão garantir que haja uma relação horizontal entre gestalt-terapeuta e cliente, possibilitando assim um processo mais autêntico na clínica.

Destaca-se que, apesar da preferência por utilizar o termo "fazer não-ético" durante as entrevistas, algumas participantes mencionaram o termo "antiético" e exemplificaram com algumas práticas. Os parâmetros éticos da profissão são diversos, porém, a prática ética, de acordo com os discursos das participantes, vai para além deles. Algumas atitudes do psicólogo deixam claro o seu caráter antiético para elas.

A participante P2 fala sobre isso ao citar a utilização de terapias alternativas como parte da psicoterapia, P4 também destaca o "poupar o cliente” enquanto uma forma do psicoterapeuta não se implicar na sua prática, tornando a assim antiética e P6 questiona psicólogos que não promovem a autonomia de seus clientes.

\section{Considerações finais}

Retomando o método fenomenológico e considerando a visão a partir do humanismo-existencialismo, Cardella (2002) afirma que este procedimento metodológico "permite verificar e renovar constantemente o conhecimento, já que concebe o homem como ser em processo, transformando e sendo transformado nas relações que estabelece com seu mundo [...]" [grifo nosso] (p. 84). É esta ideia de processo que queremos ressaltar neste trabalho.
Compreendendo, assim, a dinamicidade do tema e a importância de sua reflexão permanente.

Falar em uma ética gestáltica não pressupõe desconsiderar a ética em outros aspectos da Psicologia. É preciso destacar, contudo, que o objetivo deste trabalho buscou a partir desse recorte ampliar a compreensão dessa temática para a abordagem. Apesar de ser um tema basal para pensarmos a atuação do gestalt-terapeuta, a literatura publicada sobre este nos meios científicos ainda é escassa.

A partir das discussões levantadas neste trabalho, pensamos que refletir sobre a ética na prática psicoterapêutica precisa ser um exercício constante do profissional em campo. Não apenas enquanto leis e diretrizes, mas como reflexão crítica acerca do seu fazer técnico, teórico e prático, oferecendo assim suporte para o seu fazer clínico.

Por fim, pensar gestalticamente é se inserir num campo de relações em que as dualidades são desconstruídas, as certezas colocadas em dúvidas e os pensamentos transformados em ações, as reflexões transformadas em construções de conhecimento, o compartimentado em integrado e o acabado em inacabado, para que assim se possa, dia após dia, abrir novas gestalten e crescer em contato com o novo. Este estudo não esgota a temática da ética, em vez disso suscita a discussão e possibilita que outros olhares sejam dados a este assunto a fim de ampliá-lo e mantê-lo em debate.

\section{Referências}

Aranha, M. L. A., \& Martins, M. H. P. (2009). Filosofando: introdução à Filosofia (4a ed.). São Paulo: Moderna.

Ayres, L. S. M., \& Botelho, M. C. (2009). Diálogos entre a Ética e a Psicoterapia. Jornal do Conselho Regional de Psicologia/ $R J$ [online], 23. Disponível em: http://www.crprj.org.br/publicacoes/jornal/jornal23-lygiaayres-marianabotelho.pdf

Bauman, Z. (2011). Vida em fragmentos: sobre a ética pós-moderna. Rio de Janeiro: Zahar.

Bernardini, R. G. (1999). A Ética na Gestalt-terapia. In: VII Encontro Nacional de Gestalt-Terapia / IV Congresso Nacional da Abordagem Gestáltica. Goiânia: ITGT.

Boff, L. (1999). Saber Cuidar: ética do humano - compaixão pela terra. Petrópolis: Vozes.

Boff, L. (2012). O que significa mesmo o cuidado? Jornal do Brasil [online]. Disponível em: http://www.jb.com.br/leonardo-boff/ noticias/2012/05/21/o-que-significa-mesmo-o-cuidado/.

Bloom, D. (2011). One Good Turn Deserves Another... and Another... and Another: Personal Reflections. Gestalt Review [online], 15(3), 296-311.

Buber, M. (1981). Eu e Tu. São Paulo: Cortez (Original publicado em 1923).

Cardella, B. H. P. (2002). A construção do Psicoterapeuta: uma abordagem gestáltica. São Paulo: Summus. 
Clotet, J. (1997). Bioética como Ética Aplicada e Genética. Revista Bioética [online], 5(2), s/p.

Conselho Federal de Psicologia (2005). Código de ética profissional do psicólogo. Brasília, DF.

Cortina, A., \& Martinez, E. (2005). Ética. São Paulo: Loyola.

Forghieri, Y. C. (2004). Psicologia fenomenológica: fundamentos, métodos e pesquisas. São Paulo: Pioneira.

Frazão, L. M. (2008). Ser ético para um fazer ético. Revista Sampa GT, 5, p. 55-56.

Fuganti, L. A. (1990). Saúde, desejo e pensamento. In: Lancetti, A. (Org.). Saúde e loucura (Vol. 2) (p. 18-82). São Paulo: HUCITEC.

Lucca, F. (2007). Auto-regulação organísmica. In: D’acri, G.; Lima, P., \& Orgler, S. (Orgs). Dicionário de Gestalt-terapia - Gestaltês (p. 31-32). São Paulo: Summus.

Ludwig, M. W. B.; Zogbi, H. J.; Redivo, L. B., \& Muller, M. C. (2005, outubro). Dilemas éticos em Psicologia: Psicoterapia e pesquisa. Revista Eletrônica da Sociedade Rio-Grandense de Bioética [online], 1(1), 1-11.

Michaelis (2001). Moderno dicionário da língua portuguesa [online]. São Paulo: Melhoramentos. Disponível em: http:/ michaelis.uol.com.br/.

Moreira, D. A. (2002). O método fenomenológico na pesquisa. São Paulo: Pioneira Thompson.

Morin, E. (2005). O Método 6: ética. Porto Alegre: Sulina.

Morin, E. (2010). Para onde vai o mundo? Petrópolis: Vozes.

Morin, E. (2011). Introdução ao pensamento complexo. Porto Alegre: Sulina.

Neto, J. L. F., \& Penna, L. M. D. (2006, maio/agosto). Ética, clínica e diretrizes: a formação do psicólogo em tempos de avaliação de cursos. Psicologia em Estudo, 11(2), 381-390.

Passos, E. (2007). Ética e Psicologia: teoria e prática (1a ed.). São Paulo: Vetor.

Pereira, M. (2008). Gestalt-terapia e saúde mental: contribuições do olhar gestáltico ao campo da atenção psicossocial brasileira. Revista IGT na Rede [online], 5(9), 168-184.

Perls, F. (1988). A abordagem Gestáltica e testemunha ocular da terapia (2a ed.). Rio de Janeiro: LTC (Original publicado em 1973).

Perls, F.; Hefferline, R., \& Goodman, P. (1997). Gestalt-terapia (2a ed.). São Paulo: Summus (Original publicado em 1951).

Pinto, E. B. (2009). Psicoterapia de curta duração na abordagem gestáltica: elementos para a prática clínica. São Paulo: Summus.

Polster, E., \& Polster, M. (2001). Gestalt-terapia integrada. São Paulo: Summus (Obra original publicada em 1973).

Ribeiro, J. P. (2009). Psicoterapia de curta duração na abordagem gestáltica: elementos para a prática clínica. São Paulo: Summus.
Rosa, L. (2011). Cont(r)ato terapêutico na clínica gestáltica. Aw@re Revista Eletrônica [online], 2(1), 44-49.

Soares, L. L. M. (2009). A Gestalt-terapia na universidade: da $\mathrm{f}(\hat{o}) \mathrm{rma}$ à boa forma. Estudos e Pesquisas em Psicologia (UERJ), 9(1), 152-163.

Távora, C. B., Quadros, L. C. T., \& Soares, L. L. M. (2009, setembro). A ética como suporte: solução ou utopia para um mundo em transformação? Congressos e Encontros Nacionais da Gestalt-Terapia Brasileira [online]. Disponível em: http:/ www.igt.psc.br/ojs2/index.php/cengtb/rt/printerFriendly/186/406. Acesso em 16 de dezembro de 2012.

Turato, E. G. (2003). Tratado da Metodologia da Pesquisa ClínicoQualitativa. São Paulo: Vozes.

Yontef, G. M. (1998). Processo, diálogo e awareness: ensaios em Gestalt-terapia (2a ed.). São Paulo: Summus.

Lázaro Castro Silva Nascimento - Acadêmico do curso de Psicologia na Universidade Federal do Pará (UFPA). Pesquisador do Núcleo de Pesquisas Fenomenológicas (NUFEN) e membro do Grupo de Estudos em Gestalt-Terapia (GEGT-Belém). E-mail: lazarocastro@live.com

Kamilly Souza do Vale - Mestre em Psicologia e Professora Substituta da Universidade Federal do Pará (UFPA). Especialista em desenvolvimento infantil e Gestalt-terapeuta. Pesquisadora do Núcleo de Pesquisas Fenomenológicas (NUFEN) e coordenadora do Grupo de Estudos em Gestalt-Terapia (GEGT-Belém). E-mail: kamilly@ufpa.br

Recebido em 07.05 .13 Primeira Decisão Editorial em 06.07.13 Segunda Decisão Editorial em 03.09.13 Aceito em 06.12.13 